\title{
Polymorphisms in NFkB, PXR, LXR and risk of colorectal cancer in a prospective study of Danes
}

\author{
Vibeke Andersen ${ }^{1 *}$, Jane Christensen², Kim Overvad ${ }^{3}$, Anne Tjønneland ${ }^{2}$, Ulla Vogel ${ }^{4,5,6}$
}

\begin{abstract}
Background: Transcription factors and nuclear receptors constitute a link between exposure to heterocyclic amines and polycyclic aromatic hydrocarbons from meat and tobacco smoke and colorectal cancer (CRC) risk. The aim of this study was to investigate if polymorphisms in nuclear factor kappa-B, pregnane $X$ receptor, and liver $X$ receptor were associated with risk of CRC, and to investigate possible interactions with lifestyle factors such as smoking, meat consumption, and NSAID use.

Methods: The polymorphisms nuclear factor kappa-B (NFkB, NFKB1) -94 insertion/deletion ATTG (rs28362491), pregnane $X$ receptor (PXR, NR112) A-24381C (rs1523127), C8055T (rs2276707), A7635G (rs6785049), liver $X$ receptor (LXR- $\beta, N R 1 H 3)$ C-rs1405655T, T-rs2695121C were assessed together with lifestyle factors in a nested case-cohort study of 378 CRC cases and 756 random participants from the Danish prospective Diet, Cancer and Health study of 57,053 persons.

Results: Carriers of NFkB -94deletion were at 1.45-fold higher risk of CRC than homozygous carriers of the insertion allele (incidence rate ratio $(\mathrm{IRR})=1.45,95 \%$ confidence interval $(95 \% \mathrm{Cl}): 1.10-1.92)$. There was interaction between this polymorphism and intake of red and processed meat in relation to CRC risk. Carriers of NFkB -94deletion were at 3\% increased risk pr 25 gram meat per day (95\% Cl: 0.98-1.09) whereas homozygous carriers of the insertion were not at increased risk ( $p$ for interaction $=0.03$ ). $P X R$ and $L X R$ polymorphisms were not associated with $C R C$ risk. There was no interaction between use of nonsteroid antiinflammatory drugs (NSAID) or smoking status and NFkB, PXR or LXR polymorphisms.
\end{abstract}

Conclusions: A polymorphism in NFkB was associated with CRC risk and there was interaction between this polymorphism and meat intake in relation to CRC risk. This study suggests a role for NFkB in CRC aetiology.

\section{Background}

Colorectal cancer (CRC) constitutes the second most common cause of all cancer-related incidence and mortality in the Western World [1]. Risk factors include diet, lifestyle factors and genetic predisposition and as much as $50 \%$ of the CRC etiology has been attributed to diet $[1,2]$. Intake of red and processed meat is a risk factor for CRC and Danes have the highest meat intake per capita in the World $[1,3,4]$. The exact mechanisms by which intake of meat and processed meat promotes carcinogenesis is not clear [5]. Red and processed meat represent sources of carcinogenic heterocyclic amines (HCA), polycyclic aromatic hydrocarbons (PAH) as well as N-nitroso

\footnotetext{
* Correspondence: vibeke.andersen@viborg.rm.dk

'Medical Department, Viborg Regional Hospital, Heibergs Allé 4, DK-8800 Viborg, Denmark

Full list of author information is available at the end of the article
}

compounds caused by cooking at high temperature and by processing of meat [5]. Moreover, heme in meat may cause oxidative stress, oxidative DNA damage and carcinogenesis [6]. Tobacco smoking has also been reported to confer risk of CRC $[7,8]$ and Danes have a high prevalence of smokers $[9,10]$. Tobacco contains a large number of mutagenic and carcinogenic compounds, including $\mathrm{PAH}$, nitrosamines, and nicotine [11]. PAHs and other carcinogens from tobacco smoke may reach the intestinal lumen after swallowing of inhaled particles and smoke carcinogens may then be taken up the same way as meat carcinogens. Long term use of aspirin and other nonsteroidal anti-inflammatory drugs (NSAID) has been found to confer protection against CRC $[12,13]$. Important mechanisms may be induction of apoptosis in CRC cells by a NFkB dependent pathway as well as suppression of inflammation $[14,15]$.

\section{(Ciomed Central}


Gene-environment interaction studies have provided novel insights into the pathogenesis of CRC [16-19]. We have recently found interaction between meat intake and polymorphisms in the ATP-binding cassette (ABC) transporter $\mathrm{B} 1$ ( $A B C B 1, M D R 1)$ which encodes glycoprotein $\mathrm{P}$ involved in reverse transport of carcinogens and other xenobiotic substances [20]. The expression of human $M D R 1$ is regulated by pregnane $\mathrm{X}$ receptor (PXR) and nuclear factor $-\kappa \mathrm{B}$ (NFkB) [21] whereas other xenobiotic transporters such as $A B C C 2$ (MRP2) seem to be regulated by PXR and Liver $X$ receptor (LXR) and ABCG2 (BCRP) by Peroxisome Proliferator-Activated Receptor $\gamma$ (PPAR $\gamma$ ) [21-24].

In relation to cancer development, the most important effects of $N F k B$ activation by tobacco smoke, PAH and bacterial components is considered to be inhibition of cell apoptosis caused by the increased transcription of genes such as interleukin $1-\beta$ (IL-1 $\beta$ ) and cyclooxygenase-2 (COX-2) [25,26]. Such a role for NFkB in tumor promotion is supported by the lower tumor incidence and size of tumors after inactivation of NFkB in animal studies [27]. On the other hand, functional NFkB seem to be required to control inflammation $[28,29]$ and IL-1 $\beta$ expression [30] and to induce apoptosis [15]. A functional ATTG insertion/deletion (ins/del) polymorphism in the promoter region of $N F k B$ gene was associated with lower transcription levels of the del-allele in luciferase reporter systems [31] and risk of CRC in a Swedish, but not in a Chinese study population [32].

Activation of PXR by xenobiotica, including carcinogens, leads to up-regulation of enzymes and transporters involved in carcinogen handling including MDR1 [33] and to repression of $N F k B$ and other pro-carcinogenic genes [34]. Persons homozygous for the PXR A7635G (rs2276707) G-allele and persons carrying at least one PXR C8055T (rs6785049) T-allele have significant higher levels of intestinal $C Y P 3 A$ level following in vivo treatment with the inducer rifampin than the homozygous wildtype carriers [35]. Activation of $L X R$ by fatty acids, bacteria and cytokines leads to repression of pro-carcinogenic genes as $I L-1 \beta, C O X-2, M M P-9$ and NFkB [36]. The $L X R-\beta$ marker polymorphisms rs1405655 and rs2695121 have been investigated as risk genes for Alzheimers disease with negative results [37].

We hypothesized that carriers of the $N F \kappa B$-94del allele and PXR A7635G A-allele and C8055T C-allele would be at higher risk of CRC, especially among smokers and with high intake of red meat, whereas a protective effect of nonsteroid antiinflammatory drugs (NSAID) use was expected. We investigated the association between polymorphisms in NFkB (NFkB1) -94 insertion/deletion ATTG (rs28362491), PXR (NR1I2) A-rs1523127-C, C-rs2276707-T, A-rs6785049-G, LXR (NR1H2) C-rs1405655-T, T-rs2695121-C and risk of
CRC, as well as interactions between genes and consumption of red and processed meat, smoking status and use of NSAID in relation to the development of $\mathrm{CRC}$, in a case-cohort study nested in the prospective population-based Danish Diet, Cancer and Health study.

\section{Methods}

\section{Studied Subjects}

The subjects were selected from the Danish Diet, Cancer and Health study, an ongoing prospective cohort study [38]. Between December 1993 and May 1997, 160,725 individuals aged 50 to 64 years, born in Denmark, living in the Copenhagen and Aarhus areas and having no previous cancers at the time of invitation, were invited to participate in the study. A total of 57,053 persons accepted the invitation.

The colorectal cancer study group has been described previously $[17,19,20,39,40]$.

In total, 405 cases (184 women and 221 men) of colorectal cancer were diagnosed among the cohort members between 1994 and 2003 and registered in the files of the nationwide Danish Cancer Registry [19]. Within the cohort we defined a sub-cohort sample including 368 women and 442 men who were randomly selected. Cases and the sub-cohort sample were frequencymatched on gender. Blood samples were available for 397 cases and 800 sub-cohort members. The numbers of unknown genotypes were 16 and 37 and the numbers of unavailable food frequency questionnaire were 11 and 17 , among cases and sub-cohort members, respectively. All information on genotypes and lifestyle factors was available for 378 cases and 756 sub-cohort members who were included in the statistical analyses. A flow chart is shown in Figure 1.

\section{Lifestyle variables}

At enrolment, detailed information on diet, lifestyle, weight, height, medical treatment, environmental exposures, and other socio-economic factors were collected [38]. In the food-frequency questionnaire, meat consumption was assessed in 12 categories of predefined responses, ranking from 'never' to 'eight times or more per day'. The daily intake was then calculated by using FoodCalc [41], a program which uses population specific standardized recipes and portion sizes. Intake of red meat in grams per day was calculated by adding up intake of beef, veal, pork, lamb and offal. Intake of processed meat in grams per day was calculated by adding up intake of processed red meat, including bacon, smoked ham, salami, frankfurter, Cumberland sausage, cold cuts and liver pâté. Total dietary fibers are calculated by the AOAC methods [42]. Pearson correlation coefficients (adjusted for total energy intake) illustrating the comparison of nutrient scores estimated from the 


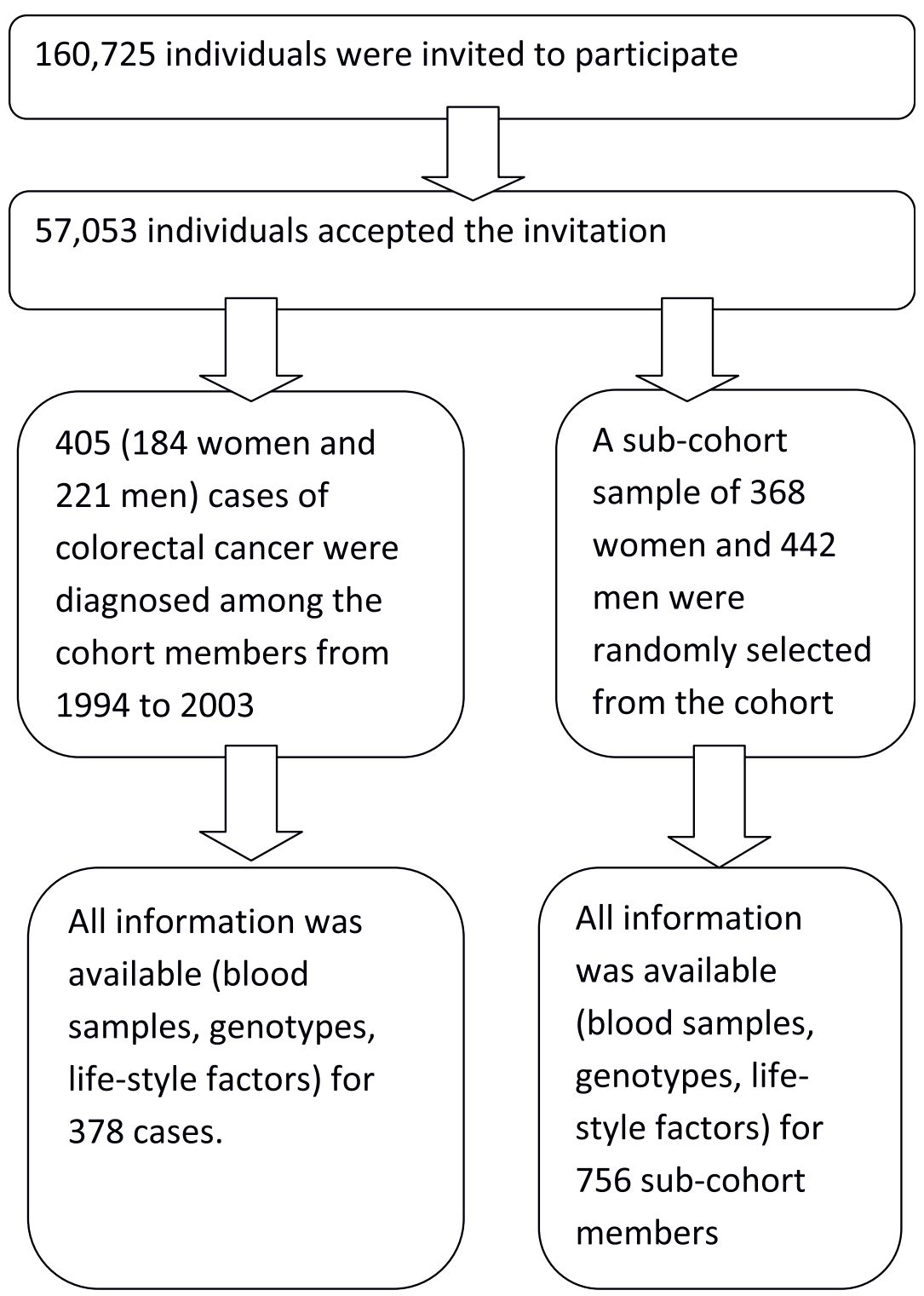

Figure 1 A flow chart showing the selection of study subjects. Between December 1993 and May 1997, 160,725 individuals aged 50 to 64 years, born in Denmark, living in the Copenhagen and Aarhus areas and having no previous cancers at the time of invitation, were invited to participate in the study. Please refer to Methods for further details.

food-frequency questionnaire and from the diet records were 0.39 and 0.53 for dietary fibers, 0.56 and 0.48 for iron, and 0.37 and 0.14 for meat for men and women, respectively [43,44].

Smoking status was categorized in three categories, never smoker, past smoker and current smoker based on the questionnaire.

The lifestyle questionnaire included questions regarding use of specific types of NSAID [45]. Based on all records, we classified study subjects according to use of "any NSAID" ( $\geq 2$ pills per month during one year) at baseline.
Data on hormone replacement therapy (HRT), alcohol intake and anthropometric measurements, and physical activity was obtained from the questionnaire as previously described [38]. The body mass index (BMI) was calculated as weight $(\mathrm{kg})$ per height $(\mathrm{m})$ squared.

\section{Blood sampling and storage}

Blood was collected at enrolment and prepared as previously described [46]. In short, a total of $30 \mathrm{ml}$ blood was collected in citrated $(2 \times 10 \mathrm{ml})$ and plain $(1 \times 10 \mathrm{ml})$ Venojects from each non-fasting participant, and lymphocytes were isolated and frozen at $-20^{\circ} \mathrm{C}$ within 2 hours. 
At the end of the day of collection, all samples were stored in liquid nitrogen, at $-150{ }^{\circ} \mathrm{C}$.

\section{Genotyping}

DNA was isolated from frozen lymphocytes as described [47]. Generally, $100 \mu \mathrm{g}$ DNA were obtained from $10^{7}$ lymphocytes.

Genotypes were determined by Taqman allelic discrimination (ABI 7500/7900HT, Applied Biosystems). Twenty ng of DNA was analysed in $4 \mu$ l volumes. Cases and sub-cohort members were mixed during genotyping and laboratory staff was blinded to case/control status during analysis. Triplicates of genotype controls of all three genotypes were included in each run. The controls were selected in pilot genotype determinations of DNA from the same cohort. Ten \% of the samples were randomly selected and genotyped again for reproducibility with $100 \%$ identity.

NFKB1 ATTG ins/del (rs28362491) was determined as described [48]. Four $\mu$ l reactions contained ca. 20 ng DNA, $2 \mu \mathrm{l}$ mastermix (Applied Biosystems, Birkerød, Denmark), $100 \mathrm{nM}$ of each probe and $900 \mathrm{nM}$ primers. Primer sequences were: F: 5'-CTA TGG ACC GCA TGA CTC TAT CAG-3' R: 5'-GGG CTC TGG CTT CCT AGC A-3'. Probe sequences were: NFKB -INS: 5'-FAM-ACC ATT GAT TGG GCC CGG-BHQ-3', NFKB-del: 5'-Yakima Yellow-CCG ACC ATT GGG CCC G-BHQ-3'.

PXR (NR1I2) A-24381C (rs1523127), C8055T (rs2276707), A7635G (rs6785049), LXR- $\beta$ (NR1H3) C-rs1405655T, and T-rs2695121C were assayed using pre-developed assays (Applied Biosystems).

\section{Statistical Analysis}

The analyses were performed according to the principles for the analysis of case-cohort studies as described by Barlow [49]. The analyses were performed unweighted. Age was used as the time scale in the Cox regression model. Tests and confidence intervals were based on Wald's test using the robust estimate of the variancecovariance matrix for the regression parameters in the Cox regression model [50].

All models were adjusted for baseline values of established risk factors for colorectal cancer such as BMI ( $\mathrm{kg} / \mathrm{m}^{2}$, continuous), NSAID (yes/no), use of HRT (never/past/current, among women), smoking status (never/past/current), and intake of dietary fibers (g/day, continuous), red meat (g/day, continuous), alcohol intake (g/day, continuous), and physical activity (hours/ day, continuous).

We investigated possible interactions between the genes and selected environmental factors using the likelihood ratio test. Tertiles of meat intake was defined as bounderies of intake of red and processed meat among the case group when devided into tertiles. Trend test were calculated using the Wald test. The procedure PHREG in SAS (release 9.1; SAS Institute Inc., Cary, $\mathrm{NC}, \mathrm{USA}$ ) was used for the statistical analyses.

\section{Ethics}

All participants gave verbal and written informed consent. Diet, Cancer and Health and the present sub-study were approved by the regional Ethics Committees on Human Studies in Copenhagen and Aarhus (Jr.nr. (KF) 11-037/01 and jr.nr. (KF)01-045/93), and by the Danish Data Protection Agency.

\section{Results}

Characteristics of the study population and risk factors for CRC are shown in Table 1. The genotype distributions among the participants in the sub-cohort sample did not deviate from Hardy-Weinberg equilibrium (results not shown).

Carriers of the $N F k B$-94del were at 1.45 -fold (95\% confidence interval (CI): 1.10-1.92) higher risk of CRC than homozygous carriers of the ins allele (Table 2) whereas $P X R$ and $L X R$ genotypes were not associated with CRC risk (Table 2). Haplotype analyses of the PXR gene showed eight different haplotypes. The most frequent haplotypes were the A-rs1523127-C/A- rs6785049G/C-rs2276707-T combinations showing CGC, AAC, and the AGC which had frequencies of $0.12,0.40$ and 0.14 , respectively. Haplotype analyses of the LXR gene showed four different haplotypes. The frequencies were for the C-rs1405655-T/T-rs2695121-C combinations TC, TT, CT and CC 0.33, 0.30, 0.24, and 0.12, respectively. No association was found between any of the eight $P X R$ or four $L X R$ haplotypes and CRC (data not shown).

Since we observed no allele-dose effects, all variant allele carriers were combined in subsequent analyses to maximize the statistical power. Del-allele carriers of $N F k B$-94ins/del were at 3\% higher risk pr 25 g meat/ day (CI: 0.98-1.09) whereas among homozygous carriers of the ins-allele, the association was in the opposite direction (IRR pr 25 g/day: 0.97, CI: 0.90-1.04, p for interaction $=0.03)($ Table 3$)$. Table 4 shows the IRRs for tertiles of intake of red and processed meat subdivided by the $N F k B$ genotypes. Among homozygous ins-allele carriers of the $N F k B$-94ins/del polymorphism, IRRs were unchanged across tertiles of meat intake, whereas for del-allele carriers, the risk of CRC was higher for the second and the third tertile of meat intake compared to the first tertile (Table 4). In this analysis, there was no statistical significant interaction.

No interactions between smoking status or NSAID use and the studied genotypes were found (Tables 5 and 6). 
Table 1 Baseline characteristics of study participants selected from the Danish Diet, Cancer and Health prospective cohort study.

\begin{tabular}{|c|c|c|c|c|}
\hline & \multicolumn{2}{|c|}{ Cases } & \multicolumn{2}{|c|}{ Sub-cohort } \\
\hline & No. (\%) & Median (5-95\%) & No. (\%) & Median (5-95\%) \\
\hline Total & $378(100)$ & & $756(100)$ & \\
\hline \multicolumn{5}{|l|}{ Gender } \\
\hline Men & $207(55)$ & & 409 (54) & \\
\hline Women & $171(45)$ & & $347(46)$ & \\
\hline Age at inclusion & & $58(51-64)$ & & $56(50-64)$ \\
\hline \multicolumn{5}{|l|}{ Topology } \\
\hline Proximal segment of colon & $42(11)$ & & & \\
\hline Distal segment of colon & 148 (39) & & & \\
\hline Rectal & $136(36)$ & & & \\
\hline Not specified & $52(14)$ & & & \\
\hline$B M I$ & & $26(21-34)$ & & $26(21-33)$ \\
\hline \multicolumn{5}{|l|}{ Food intake } \\
\hline Alcohol, g/day & & $14(1-69)$ & & $13(1-61)$ \\
\hline Red meat, g/day & & $82(37-171)$ & & $82(32-177)$ \\
\hline Processed meat, g/day & & $26(6-79)$ & & $25(4-76)$ \\
\hline Dietary fibres g/day & & $20(10-32)$ & & $21(11-34)$ \\
\hline \multicolumn{5}{|l|}{ Smoking status at inclusion } \\
\hline Never & $116(31)$ & & $250(33)$ & \\
\hline Former & $113(30)$ & & $238(31)$ & \\
\hline Present & $149(39)$ & & $268(35)$ & \\
\hline \multicolumn{5}{|l|}{ NSAID use } \\
\hline No & $123(33)$ & & $234(31)$ & \\
\hline Yes & $255(67)$ & & $522(69)$ & \\
\hline \multicolumn{5}{|l|}{ HRT use among women } \\
\hline Never & $100(58)$ & & $186(54)$ & \\
\hline Former & $26(15)$ & & $58(17)$ & \\
\hline Present & $45(26)$ & & $103(30)$ & \\
\hline
\end{tabular}

Observed median values (5-95 percentiles) or percents of the distribution of baseline characteristics among cases and members of the comparison group.

\section{Discussion}

Carriers of the del-allele of $N F k B$-94ins/del polymorphism were at statistically significantly higher risk of CRC than the homozygous carriers of the ins-allele.

Prospective studies have the advantage in relation to examining gene-environmental interactions that they are not encumbered by recall bias. In the present study, cases and cohort sample were selected from the same cohort, which together with complete follow up of the participants minimised the risk of selection bias. We have used the case-cohort study design in the present study. The case-cohort analysis is a more flexible design than a nested case-control design [49]. It permits us to use one large, randomly selected comparison group as comparison group for several nested studies within the Diet, Cancer and Health cohort, saving resources and valuable DNA, and the obtained risk estimates can be related directly to the cohort, which is population-based. We have previously used the same design in other studies of colorectal cancer $[17,19,20,39,51]$, lung cancer [52-55], and coronary heart disease [56-59].

A main strength of our study is a well characterized study population. Information on lifestyle factors were collected at enrolment for all participants which minimised the risk of differential misclassification of cases and comparison group. However, lifestyle factors were only collected once, and may thus not be representative for the lifestyle during follow-up. This is, however, not expected to result in differential misclassification. Furthermore, information on food intake was based on a semi-quantitatively food frequency questionnaire $[38,44]$, which was evaluated and found usable [43]. The results were adjusted for known confounding factors affecting the risk of CRC in this cohort including dietary factors, body mass index (BMI), alcohol, smoking status, physical activity and NSAID use [1]. An additional strength of the present study is the high exposure of red and processed meat and tobacco smoke in the present 
Table 2 Incidence rate ratios (IRR) for colorectal cancer for the studied gene polymorphisms.

\begin{tabular}{|c|c|c|c|c|c|c|c|}
\hline & $\mathrm{N}_{\text {cases }}$ & $\mathrm{N}_{\text {sub-cohort }}$ & $\mathrm{IRR}^{\mathrm{A}}$ & $95 \% \mathrm{Cl}$ & $\mathrm{IRR}^{\mathrm{B}}$ & $95 \% \mathrm{Cl}$ & p-value \\
\hline \multicolumn{8}{|l|}{ NFkB -94ins/del } \\
\hline$\|$ & 121 & 307 & 1.00 & - & 1.00 & - & 0.03 \\
\hline ID & 195 & 347 & 1.46 & $(1.10-1.93)$ & 1.44 & $(1.07-1.92)$ & \\
\hline DD & 62 & 102 & 1.50 & $(1.02-2.22)$ & 1.50 & $(1.00-2.25)$ & \\
\hline ID and DD & 257 & 449 & 1.47 & $(1.12-1.92)$ & 1.45 & $(1.10-1.92)$ & \\
\hline \multicolumn{8}{|l|}{ PXR rs1523127 } \\
\hline AA & 127 & 257 & 1.00 & - & 1.00 & - & 0.78 \\
\hline$A C$ & 188 & 371 & 0.99 & $(0.74-1.31)$ & 0.99 & $(0.74-1.32)$ & \\
\hline CC & 63 & 128 & 1.08 & $(0.74-1.57)$ & 1.12 & $(0.77-1.65)$ & \\
\hline$A C$ and $C C$ & 251 & 499 & 1.01 & $(0.77-1.32)$ & 1.02 & $(0.77-1.34)$ & \\
\hline \multicolumn{8}{|l|}{ PXR rs2276707 } \\
\hline CC & 237 & 441 & 1.00 & - & 1.00 & - & 0.66 \\
\hline CT & 122 & 270 & 0.87 & $(0.67-1.14)$ & 0.88 & $(0.67-1.17)$ & \\
\hline$\pi$ & 19 & 45 & 0.83 & $(0.46-1.49)$ & 0.89 & $(0.49-1.62)$ & \\
\hline$C T$ and $\Pi \mathrm{T}$ & 141 & 315 & 0.87 & $(0.67-1.12)$ & 0.88 & $(0.68-1.15)$ & \\
\hline \multicolumn{8}{|l|}{ PXR rs6785049 } \\
\hline $\mathrm{AA}$ & 136 & 259 & 1.00 & - & 1.00 & - & 0.60 \\
\hline$A G$ & 187 & 398 & 0.91 & $(0.69-1.21)$ & 0.90 & $(0.67-1.21)$ & \\
\hline GG & 55 & 99 & 1.10 & $(0.74-1.64)$ & 1.09 & $(0.72-1.65)$ & \\
\hline $\mathrm{AG}$ and $\mathrm{GG}$ & 242 & 497 & 0.95 & $(0.73-1.24)$ & 0.94 & $(0.71-1.24)$ & \\
\hline \multicolumn{8}{|l|}{ LXR rs1405655 } \\
\hline CC & 169 & 347 & 1.00 & - & 1.00 & - & 0.88 \\
\hline CT & 169 & 335 & 1.00 & $(0.77-1.31)$ & 1.00 & $(0.76-1.31)$ & \\
\hline$\pi$ & 40 & 74 & 1.05 & $(0.68-1.63)$ & 1.12 & $(0.71-1.76)$ & \\
\hline $\mathrm{CT}$ and $\mathrm{TT}$ & 209 & 409 & 1.01 & $(0.79-1.31)$ & 1.02 & $(0.79-1.32)$ & \\
\hline \multicolumn{8}{|l|}{ LXR rs2695121 } \\
\hline$T T$ & 117 & 221 & 1.00 & - & 1.00 & - & 0.36 \\
\hline CT & 187 & 368 & 0.93 & $(0.69-1.25)$ & 0.91 & $(0.67-1.23)$ & \\
\hline CC & 74 & 167 & 0.78 & $(0.54-1.12)$ & 0.77 & $(0.53-1.11)$ & \\
\hline $\mathrm{CT}$ and $\mathrm{CC}$ & 261 & 535 & 0.88 & $(0.67-1.17)$ & 0.86 & $(0.65-1.15)$ & \\
\hline
\end{tabular}

${ }^{\mathrm{A}}$ Crude (adjusted for age and sex).

${ }^{B}$ Additionally adjusted for status of HRT (women only), smoking status, alcohol, dietary fibre, red meat, physical activity and BMI and NSAID use.

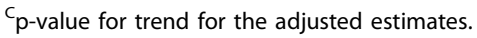

study [3,9]. Limitations of the study include the relatively small sample size. Therefore, heterozygous and homozygous variant genotype carriers were combined for the analyses of interactions to obtain sufficient statistical power. Nevertheless, in the light of the obtained Pvalues and the number of statistical testes performed, we cannot exclude that our positive findings may be due to chance.

We found a weak interaction between $N F k B$-94ins/del polymorphism and intake of red and processed meat in relation to CRC risk (Table 3). In the interaction analysis, we calculated the slopes of two curves describing the relationship between meat intake and CRC risk for homozygous carriers of the ins-allele and for carriers of the del-allele, respectively. However, either of the slopes is statistically significantly different from 1 , as indicted by the confidence intervals. However, the two slopes were statistically significantly different from each other as indicated by the p-value for the interaction $(\mathrm{p}=0.03)$. Furthermore, among homozygous carriers of the ins-allele of the $N F k B$-94ins/del polymorphism, risk of CRC was unchanged across tertiles of meat intake, whereas for del-allele carriers, the risk of CRC was higher for the second and the third tertile of meat intake compared to the first tertile (Table 4). In this analysis, there was no statistically significant interaction. Our study thus suggests that the NFkB polymorphism may be most important in study populations with high consumption of red and processed meat. The NFkB -94ins/del del-allele was associated with risk of CRC among Swedes, whereas no association was found among Chinese [32]. Hence, the difference between the findings in the Danish and Swedish on one hand and the Chinese on the other may be related to differences 
Table 3 Incidence rate ratios (IRR) for colorectal cancer per additional intake of $\mathbf{2 5} \mathbf{g}$ red or processed meat subdivided by the studied genotypes.

\begin{tabular}{|c|c|c|c|c|c|c|c|}
\hline & \multirow[b]{2}{*}{$\mathrm{N}_{\text {cases }}$} & \multirow[b]{2}{*}{$N_{\text {sub-cohort }}$} & \multicolumn{5}{|c|}{ Red and processed meat } \\
\hline & & & $\mathrm{IRR}^{\mathrm{A}}$ & $95 \% \mathrm{Cl}$ & $\mathrm{IRR}^{\mathrm{B}}$ & $95 \% \mathrm{Cl}$ & p-value ${ }^{c}$ \\
\hline \multicolumn{8}{|l|}{ NFkB -94ins/del } \\
\hline$\|$ & 121 & 307 & 0.96 & $(0.90-1.03)$ & 0.97 & $(0.90-1.04)$ & 0.03 \\
\hline ID and DD & 257 & 449 & 1.03 & $(0.98-1.08)$ & 1.03 & $(0.98-1.09)$ & \\
\hline \multicolumn{8}{|l|}{ PXR rs1523127 } \\
\hline AA & 127 & 257 & 1.04 & $(0.98-1.12)$ & 1.04 & $(0.97-1.12)$ & 0.28 \\
\hline$A C$ and $C C$ & 251 & 499 & 1.01 & $(0.96-1.06)$ & 1.01 & $(0.96-1.07)$ & \\
\hline \multicolumn{8}{|l|}{ PXR rs2276707 } \\
\hline $\mathrm{CC}$ & 237 & 441 & 1.02 & $(0.97-1.08)$ & 1.02 & $(0.97-1.08)$ & 0.53 \\
\hline $\mathrm{CT}$ and $\mathrm{TT}$ & 141 & 315 & 1.01 & $(0.95-1.07)$ & 1.01 & $(0.94-1.08)$ & \\
\hline \multicolumn{8}{|l|}{ PXR rs6785049 } \\
\hline AA & 136 & 259 & 1.01 & $(0.95-1.07)$ & 1.01 & $(0.95-1.08)$ & 0.72 \\
\hline$A G$ and $G G$ & 242 & 497 & 1.02 & $(0.97-1.08)$ & 1.02 & $(0.97-1.08)$ & \\
\hline \multicolumn{8}{|l|}{ LXR rs 1405655} \\
\hline $\mathrm{CC}$ & 169 & 347 & 1.02 & $(0.97-1.07)$ & 1.02 & $(0.96-1.08)$ & 0.91 \\
\hline$C T$ and $\Pi$ & 209 & 409 & 1.02 & $(0.96-1.08)$ & 1.02 & $(0.96-1.08)$ & \\
\hline \multicolumn{8}{|l|}{ LXR rs2695121 } \\
\hline$\pi$ & 117 & 221 & 1.04 & $(0.98-1.12)$ & 1.05 & $(0.97-1.12)$ & 0.28 \\
\hline $\mathrm{CT}$ and $\mathrm{CC}$ & 261 & 535 & 1.01 & $(0.96-1.07)$ & 1.01 & $(0.96-1.07)$ & \\
\hline
\end{tabular}

${ }^{A}$ Crude (adjusted for age and sex).

${ }^{B}$ Additionally adjusted for status of HRT (women only), smoking status, alcohol, dietary fibre, physical activity, NSAID use and BMI.

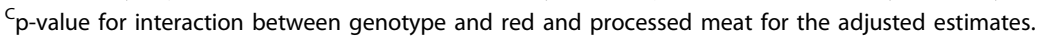

in meat exposure. Meat intake is much high in high income countries, including Denmark and Sweden, compared to low income countries, including China, respectively [3].

We have previously found interaction between meat intake and polymorphisms in the xenobiotic transporter MDR1 in relation to CRC in this study group [20]. Combined carriers of MDR1 intron 3 G-rs3789243A Aallele and $N F k B$-94ins/del del-allele have an IRR of 1.85 (95\% confidence interval $(\mathrm{CI}): 1.15-3.00, \mathrm{p}=0.007$ ) compared to the homozygous G-allele and ins-allele carriers, suggesting additive but no synergistic effect by having both risk alleles. However, the statistical power to explore gene-gene interactions was low. The two studies may suggest that a lower NFkB response by the $N F k B$ del-allele carriers after stimulation by intestinal carcinogens may lead to a lower expression of the MDR1 [21] and, thus, a lower transport activity and, eventually, an impaired defence against intestinal uptake of luminal carcinogens compared to homozygous ins-allele carriers. Furthermore, interaction between meat and $N F k B$ may be caused by a lower activation of $N F k B$ del-allele relative to the ins-allele resulting in a high load of reactive oxygen species provided by heme degradation and which may contribute to carcinogenesis [60].

We found no interaction between the NFkB -94ins/del polymorphism and smoking status, suggesting that the carcinogen exposure from tobacco smoke, which comes from ingestion of inhaled tobacco smoke particles, is less than the carcinogen exposure from ingestion of red

Table 4 Incidence rate ratios (IRR) for colorectal cancer for tertiles of intake of red and processed meat subdivided by the NFkB genotypes.

\begin{tabular}{|c|c|c|c|c|c|c|c|c|c|c|c|c|}
\hline & \multicolumn{6}{|c|}{ Red and processed meat } & \multicolumn{5}{|c|}{ IRR $^{\mathrm{A}} 95 \% \mathrm{Cl}$} & \multirow[t]{2}{*}{$p$-value ${ }^{B}$} \\
\hline & \multicolumn{2}{|c|}{ 1. tertile } & \multicolumn{2}{|c|}{ 2. tertile } & \multicolumn{2}{|c|}{ 3. tertile } & \multicolumn{5}{|c|}{ Red and processed meat } & \\
\hline & $\mathrm{N}_{\mathrm{C}}$ & $\mathrm{N}_{\mathrm{s}}$ & $\mathrm{N}_{\mathrm{C}}$ & $\mathrm{N}_{\mathrm{S}}$ & $\mathrm{N}_{\mathrm{C}}$ & $\mathrm{N}_{\mathrm{S}}$ & $<91.4 \mathrm{~g} /$ day & 91.4 & $0.2 \mathrm{~g} / \mathrm{day}$ & & $.2 \mathrm{~g} / \mathrm{day}$ & \\
\hline \multicolumn{13}{|l|}{ NFkB -94ins/del } \\
\hline$\|$ & 46 & 107 & 35 & 98 & 40 & 102 & 1.00 & 0.88 & $(0.50-1.54)$ & 1.07 & $(0.61-1.88)$ & 0.16 \\
\hline ID and DD & 78 & 157 & 91 & 137 & 88 & 155 & $(0.75-1.91)$ & 1.70 & $(1.06-2.74)$ & 1.44 & $(0.89-2.34)$ & \\
\hline
\end{tabular}

${ }^{A}$ Adjusted for status of HRT (women only), smoking status, alcohol, dietary fibre, BMI, physical activity and NSAID use.

${ }^{B}$ p-value for interaction. 
Table 5 Interaction between the studied polymorphisms and smoking status.

\begin{tabular}{|c|c|c|c|c|c|c|c|c|c|c|c|c|c|}
\hline & \multicolumn{6}{|c|}{ Smoking } & \multirow{2}{*}{\multicolumn{6}{|c|}{$\begin{array}{c}\mathrm{IRR}^{\mathrm{A}} \text { 95\% CI } \\
\text { Smoking }\end{array}$}} & \multirow[t]{3}{*}{ p-value ${ }^{B}$} \\
\hline & \multicolumn{2}{|c|}{ Never } & \multicolumn{2}{|c|}{ Past } & \multicolumn{2}{|c|}{ Current } & & & & & & & \\
\hline & $\mathrm{N}_{\mathrm{C}}$ & $\mathrm{N}_{\mathrm{S}}$ & $\mathrm{N}_{\mathrm{C}}$ & $\mathrm{N}_{\mathrm{S}}$ & $\mathrm{N}_{\mathrm{C}}$ & $\mathrm{N}_{\mathrm{S}}$ & \multicolumn{2}{|r|}{ Never } & & Past & \multicolumn{2}{|c|}{ Current } & \\
\hline$\|$ & 37 & 101 & 37 & 101 & 47 & 105 & 1.00 & - & 0.89 & $(0.51-1.55)$ & 1.15 & $(0.67-1.97)$ & 0.84 \\
\hline ID and DD & 79 & 149 & 76 & 137 & 102 & 163 & 1.45 & $(0.89-2.37)$ & 1.41 & $(0.86-2.33)$ & 1.55 & $(0.96-2.51)$ & \\
\hline \multicolumn{14}{|l|}{ PXR rs1523127 } \\
\hline AA & 33 & 94 & 42 & 76 & 52 & 87 & 1.00 & - & 1.37 & $(0.77-2.47)$ & 1.55 & $(0.89-2.70)$ & 0.08 \\
\hline$A C$ and $C C$ & 83 & 156 & 71 & 162 & 97 & 181 & 1.49 & $(0.90-2.45)$ & 1.15 & $(0.69-1.91)$ & 1.38 & $(0.84-2.28)$ & \\
\hline \multicolumn{14}{|l|}{ PXR rs2276707 } \\
\hline CC & 63 & 141 & 70 & 135 & 104 & 165 & 1.00 & - & 1.01 & $(0.65-1.57)$ & 1.24 & $(0.82-1.87)$ & 0.43 \\
\hline $\mathrm{CT}$ and $\Pi \mathrm{T}$ & 53 & 109 & 43 & 103 & 45 & 103 & 1.06 & $(0.66-1.68)$ & 0.89 & $(0.54-1.47)$ & 0.93 & $(0.57-1.51)$ & \\
\hline \multicolumn{14}{|l|}{ PXR rs6785049 } \\
\hline AA & 40 & 89 & 38 & 85 & 58 & 85 & 1.00 & - & 0.92 & $(0.52-1.61)$ & 1.37 & $(0.80-2.33)$ & 0.28 \\
\hline$A G$ and $G G$ & 76 & 161 & 75 & 153 & 91 & 183 & 1.06 & $(0.65-1.72)$ & 1.00 & $(0.61-1.63)$ & 1.04 & $(0.64-1.67)$ & \\
\hline \multicolumn{14}{|l|}{ LXR rs 1405655} \\
\hline $\mathrm{CC}$ & 49 & 117 & 54 & 116 & 66 & 114 & 1.00 & - & 0.93 & $(0.56-1.54)$ & 1.18 & $(0.72-1.92)$ & 0.83 \\
\hline $\mathrm{CT}$ and $\Pi \mathrm{T}$ & 67 & 133 & 59 & 122 & 83 & 154 & 1.07 & $(0.66-1.72)$ & 1.01 & $(0.62-1.64)$ & 1.11 & $(0.71-1.74)$ & \\
\hline \multicolumn{14}{|l|}{ LXR rs2695121 } \\
\hline$\pi$ & 36 & 74 & 35 & 63 & 46 & 84 & 1.00 & - & 1.12 & $(0.61-2.07)$ & 1.20 & $(0.67-2.13)$ & 0.67 \\
\hline $\mathrm{CT}$ and $\mathrm{CC}$ & 80 & 176 & 78 & 175 & 103 & 184 & 0.98 & $(0.59-1.63)$ & 0.85 & $(0.51-1.42)$ & 1.03 & $(0.63-1.70)$ & \\
\hline
\end{tabular}

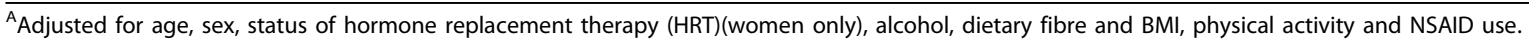

B P-value for interaction.

Table 6 Interaction between gene polymorphisms and NSAID use.

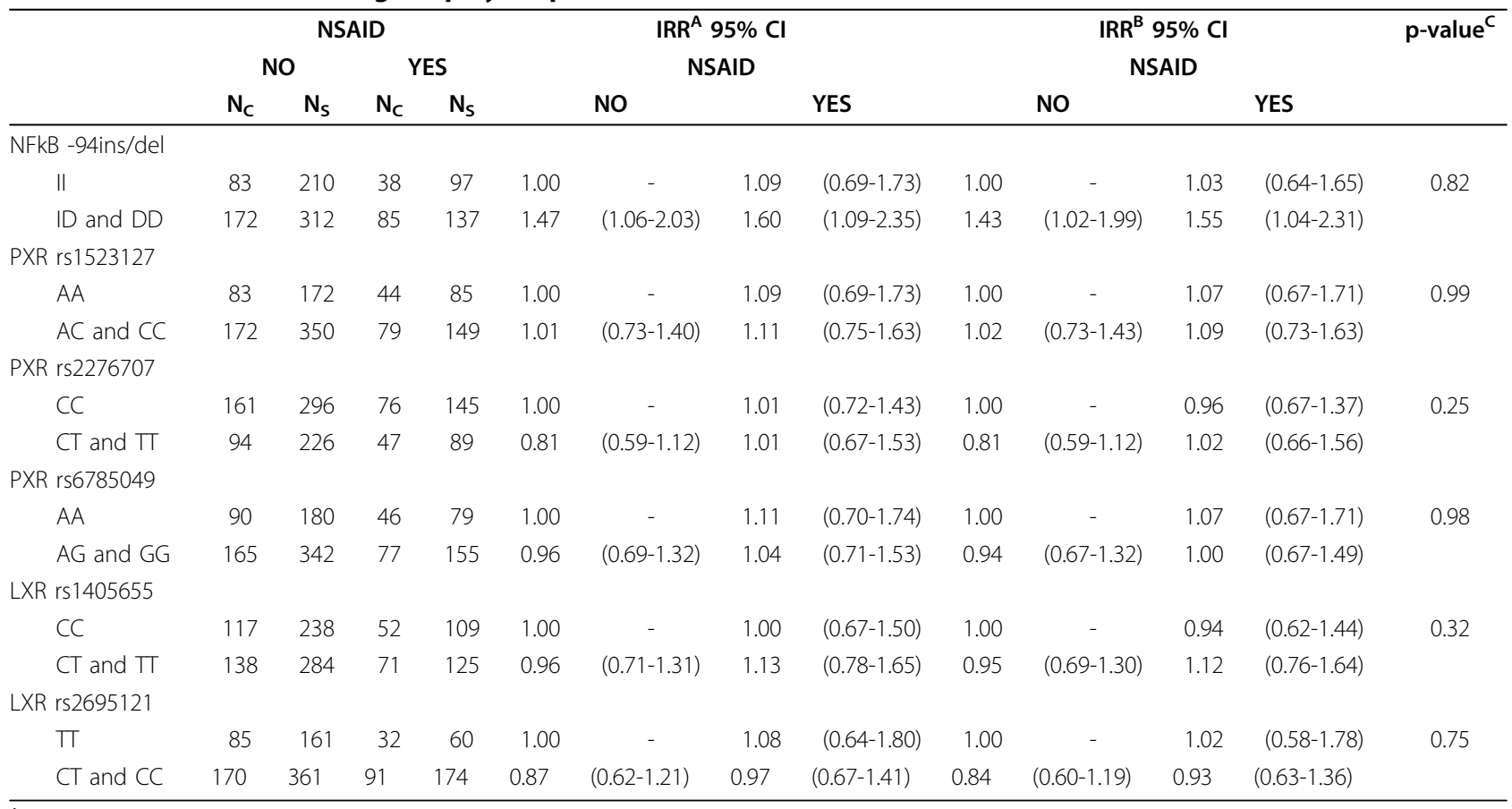

${ }^{A}$ Crude (adjusted for age and sex)

${ }^{B}$ Additionally adjusted for status of hormone replacement therapy (HRT), smoking status, alcohol, dietary fibre, red meat, physical activity and BMI.

C P-value for interaction for the adjusted estimates. 
and processed meat. This is in accordance with our previous finding of smoking being a weaker risk factor for CRC than red and processed meat [20].

We found no statistically significant associations between the PXR and $L X R$ polymorphisms and CRC risk, and no interaction with smoking status, use of NSAID, or intake of red and processed meat. These two genes have not previously been investigated in relation to $\mathrm{CRC}$. We had from $73 \%$ to $99 \%$ chance to detect a dominant effect of the three studied polymorphisms in PXR using the ORs from the study of Dring [61] of 1.32.9 and similarly more than $84 \%$ chance of detecting a dominant effect with an OR of 1.5 in $L X R$. Our findings do therefore not support important roles of $P X R$ and $L X R$ in CRC etiology. This is in accordance with the observation that $N F k B$ activation suppress the action of $P X R$ and vice versa [62,63].

We found no interaction between NSAID use and $N F \kappa B, P X R$ and $L X R$ genotypes. A risk reducing affect of NSAID may be dependent on functional NF $\kappa \mathrm{B}$, as aspirin has been shown to induce apoptosis in intestinal cell lines by a NF $\kappa$ B dependent mechanism [64]. Longterm use of NSAID was associated with a protective effect against CRC in the "Diet, Cancer and Health" cohort, used in the present study [45]. Hence, the results do not support important roles of the studied genotypes in interaction with NSAID in CRC aetiology.

\section{Conclusions}

The present study indicated that the ins/del $N F k B$ polymorphism may be involved in CRC etiologi. The ins/del $N F k B$ polymorphism may affect the risk of CRC by exposure of meat as carriers of the $N F k B$ del-allele were more susceptible to meat carcinogens than homozygous ins-allele carriers. This is the first study finding interaction between $N F k B$ and meat intake in relation to CRC. However, the findings must be further evaluated in large populations with high meat intake.

\section{Abbreviations \\ ABCB2: ATP-binding cassette (ABC) transporter B2 (MDR1); ABCC2: ATP- binding cassette (ABC) transporter $C 2$ (MRP2); ABCG2: ATP-binding cassette $(\mathrm{ABC})$ transporter B2 (BCRP); COX-2: cyclooxygenase-2; CRC: colorectal cancer; IL-1 $\beta$ : interleukin 1- $\beta$; LXR: Liver $X$ receptor (NR1H3); MMP-9: matrix metalloproteinase-9; LPS: lipopolysaccharide; NSAID: non-steroidal anti- inflammatory drugs; NFkB: nuclear factor kappa-B (NFKB1); PXR: pregnane X receptor (NR112); SNP: single nucleotide polymorphism; TNF- $\alpha$ : tumor nekrosis factor- $\alpha$; VEGF: vascular endothelial growth factor;}

\section{Acknowledgements}

Lars Bentzen is thanked for excellent technical assistance. We thank the staff at the Library, Viborg Regional Hospital. This work was supported by

"Familien Erichsens Mindefond", The Lundbeck Foundation, "Johs M Klein og Hustrus mindelegat", "Agnete Løvgreens Legat", the Danish Cancer Society, grant DP00027, the grant ENGAGE from the Novo Nordisk Foundation and a grant from the Danish Ministry of Health, Research Centre for Environmental Health's Fund, ENGAGE.

\section{Author details}

${ }^{1}$ Medical Department, Viborg Regional Hospital, Heibergs Allé 4, DK-8800 Viborg, Denmark. ${ }^{2}$ Danish Cancer Society, Institute of Cancer Epidemiology, DK-2100 Copenhagen, Denmark. ${ }^{3}$ Department of Epidemiology, School of Public Health, Aarhus University, Aarhus, Denmark. ${ }^{4}$ National Research Centre for the Working Environment, DK-2100 Copenhagen, Denmark. ${ }^{5}$ National Food Institute, Technical University of Denmark, DK-2860 Soborg, Denmark. ${ }^{6}$ Institute of Science, Systems and Models, University of Roskilde, DK-4000 Roskilde, Denmark.

\section{Authors' contributions}

UV carried out the molecular genetic studies. UV, KO, AT participated in the design of the study and JC performed the statistical analysis. VA conceived the study and drafted the manuscript. All authors read and approved the final manuscript.

\section{Competing interests}

The authors declare that they have no competing interests.

Received: 21 January 2010 Accepted: 13 September 2010 Published: 13 September 2010

\section{References}

1. Huxley RR, nsary-Moghaddam A, Clifton P, Czernichow S, Parr CL, Woodward M: The impact of dietary and lifestyle risk factors on risk of colorectal cancer: a quantitative overview of the epidemiological evidence. Int J Cancer 2009, 125:171-180.

2. Aggarwal BB, Vijayalekshmi RV, Sung B: Targeting inflammatory pathways for prevention and therapy of cancer: short-term friend, long-term foe. Clin Cancer Res 2009, 15:425-430.

3. World Resources Institue, Earth Trends, The environmental information portal. 2009 [http://earthtrends.wri.org/], Ref Type: Internet Communication.

4. World Cancer Research Fund/American Institute for CancerResearch FNPAatoCaGPA. Washington, DC 2007 [http://www.dietandcancerreport. org/], Ref Type: Internet Communication.

5. Santarelli RL, Pierre F, Corpet DE: Processed meat and colorectal cancer: a review of epidemiologic and experimental evidence. Nutr Cancer 2008, 60:131-144.

6. Oates PS, West AR: Heme in intestinal epithelial cell turnover, differentiation, detoxification, inflammation, carcinogenesis, absorption and motility. World J Gastroenterol 2006, 12:4281-4295.

7. Liang PS, Chen TY, Giovannucci E: Cigarette smoking and colorectal cancer incidence and mortality: systematic review and meta-analysis. Int J Cancer 2009, 124:2406-2415

8. Tsoi KK, Pau CY, Wu WK, Chan FK, Griffiths S, Sung JJ: Cigarette smoking and the risk of colorectal cancer: a meta-analysis of prospective cohort studies. Clin Gastroenterol Hepatol 2009, 7:682-688.

9. WHO Regional Office for Europe. Tobacco control database. 2009 [http://data.euro.who.int/tobacco/], Ref Type: Internet Communication.

10. Richard Peto, Lopez Alan D, Jillian Boreham, Thun Michael: Mortality from smoking in developed contries 1950-2000. 2009 [http://www.ctsu.ox.ac. uk/ tobacco], Ref Type: Internet Communication.

11. Seitz M, Wirthmuller U, Moller B, Villiger PM: The -308 tumour necrosis factor-alpha gene polymorphism predicts therapeutic response to TNFalpha-blockers in rheumatoid arthritis and spondyloarthritis patients. Rheumatology (Oxford) 2007, 46:93-96.

12. Flossmann E, Rothwell PM: Effect of aspirin on long-term risk of colorectal cancer: consistent evidence from randomised and observational studies. Lancet 2007, 369:1603-1613.

13. Friis S, Poulsen AH, Sorensen HT, Tjonneland A, Overvad K, Vogel U, et al: Aspirin and other non-steroidal anti-inflammatory drugs and risk of colorectal cancer: A Danish cohort study. Cancer Causes Control 2009.

14. Elwood PC, Gallagher AM, Duthie GG, Mur LA, Morgan G: Aspirin, salicylates, and cancer. Lancet 2009, 373:1301-1309.

15. Stark LA, Din FV, Zwacka RM, Dunlop MG: Aspirin-induced activation of the NF-kappaB signaling pathway: a novel mechanism for aspirinmediated apoptosis in colon cancer cells. FASEB J 2001, 15:1273-1275.

16. Goel A, Boland CR: Recent insights into the pathogenesis of colorectal cancer. Curr Opin Gastroenterol 2009. 
17. Vogel U, Christensen J, Dybdahl M, Friis S, Hansen RD, Wallin $H$, et al: Prospective study of interaction between alcohol, NSAID use and polymorphisms in genes involved in the inflammatory response in relation to risk of colorectal cancer. Mutat Res 2007, 624:88-100.

18. Andersen V, Agerstjerne L, Jensen D, Ostergaard M, Saebo M, Hamfjord J, et al: The multidrug resistance 1 (MDR1) gene polymorphism Grs3789243-A is not associated with disease susceptibility in Norwegian patients with colorectal adenoma and colorectal cancer; a case control study. BMC Med Genet 2009, 10:18.

19. Hansen RD, Sorensen M, Tjonneland A, Overvad K, Wallin H, RaaschouNielsen O, et al: XPA A23G, XPC Lys939GIn, XPD Lys751GIn and XPD Asp312Asn polymorphisms, interactions with smoking, alcohol and dietary factors, and risk of colorectal cancer. Mutat Res 2007, 619:68-80.

20. Andersen V, Ostergaard M, Christensen J, Overvad K, Tjonneland A, Vogel U: Polymorphisms in the xenobiotic transporter Multidrug Resistance 1 (MDR1) gene and interaction with meat intake in relation to risk of colorectal cancer in a Danish prospective case-cohort study. BMC Cancer 2009, 9:407.

21. Scotto KW: Transcriptional regulation of $\mathrm{ABC}$ drug transporters. Oncogene 2003, 22:7496-7511.

22. Urquhart BL, Ware JA, Tirona RG, Ho RH, Leake BF, Schwarz UI, et al: Breast cancer resistance protein (ABCG2) and drug disposition: intestinal expression, polymorphisms and sulfasalazine as an in vivo probe. Pharmacogenet Genomics 2008, 18:439-448.

23. Teng S, Piquette-Miller M: Regulation of transporters by nuclear hormone receptors: implications during inflammation. Mol Pharm 2008, 5:67-76.

24. Chisaki I, Kobayashi M, Itagaki S, Hirano T, Iseki K: Liver X receptor regulates expression of MRP2 but not that of MDR1 and BCRP in the liver. Biochim Biophys Acta 2009, 1788:2396-2403.

25. Wang D, DuBois RN: Inflammatory mediators and nuclear receptor signaling in colorectal cancer. Cell Cycle 2007, 6:682-685.

26. Karin M: Nuclear factor-kappaB in cancer development and progression. Nature 2006, 441:431-436.

27. Kundu JK, Surh YJ: Inflammation: gearing the journey to cancer. Mutat Res 2008, 659:15-30.

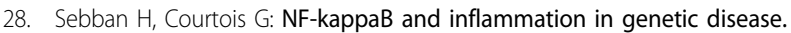
Biochem Pharmacol 2006, 72:1153-1160.

29. De Vry CG, Prasad S, Komuves L, Lorenzana C, Parham C, Le T, et al: Nonviral delivery of nuclear factor-kappaB decoy ameliorates murine inflammatory bowel disease and restores tissue homeostasis. Gut 2007, 56:524-533.

30. Greten FR, Arkan MC, Bollrath J, Hsu LC, Goode J, Miething C, et al: NFkappaB is a negative regulator of IL-1beta secretion as revealed by genetic and pharmacological inhibition of IKKbeta. Cell 2007, 130:918-931.

31. Karban AS, Okazaki T, Panhuysen Cl, Gallegos T, Potter JJ, Bailey-Wilson JE, et al: Functional annotation of a novel NFKB1 promoter polymorphism that increases risk for ulcerative colitis. Hum Mol Genet 2004, 13:35-45.

32. Lewander A, Butchi AK, Gao J, He LJ, Lindblom A, Arbman G, et al: Polymorphism in the promoter region of the NFKB1 gene increases the risk of sporadic colorectal cancer in Swedish but not in Chinese populations. Scand J Gastroenterol 2007, 42:1332-1338.

33. di MA, Marinis ED, Ascenzi P, Marino M: Nuclear receptors CAR and PXR: Molecular, functional, and biomedical aspects. Mol Aspects Med 2009, 30:297-343.

34. Zhou C, Tabb MM, Nelson EL, Grun F, Verma S, Sadatrafiei A, et al: Mutual repression between steroid and xenobiotic receptor and NF-kappaB signaling pathways links xenobiotic metabolism and inflammation. J Clin Invest 2006, 116:2280-2289.

35. Zhang J, Kuehl P, Green ED, Touchman JW, Watkins PB, Daly A, et al: The human pregnane $X$ receptor: genomic structure and identification and functional characterization of natural allelic variants. Pharmacogenetics 2001, 11:555-572.

36. Rizzo G, Fiorucci S: PPARs and other nuclear receptors in inflammation. Curr Opin Pharmacol 2006, 6:421-427.

37. Infante J, Rodriguez-Rodriguez E, Mateo I, Llorca J, Vazquez-Higuera JL, Berciano J, et al: Gene-gene interaction between heme oxygenase- 1 and liver X receptor-beta and Alzheimer's disease risk. Neurobiol Aging 2008.

38. Tjonneland A, Olsen A, Boll K, Stripp C, Christensen J, Engholm G, et al: Study design, exposure variables, and socioeconomic determinants of participation in Diet, Cancer and Health: a population-based prospective cohort study of 57,053 men and women in Denmark. Scand J Public Health 2007, 35:432-441.

39. Hansen R, Saebo M, Skjelbred CF, Nexo BA, Hagen PC, Bock G, et al: GPX Pro198Leu and OGG1 Ser326Cys polymorphisms and risk of development of colorectal adenomas and colorectal cancer. Cancer Lett 2005, 229:85-91.

40. Hansen RD, Sorensen M, Tjonneland A, Overvad K, Wallin H, RaaschouNielsen O, et al: A haplotype of polymorphisms in ASE-1, RAI and ERCC1 and the effects of tobacco smoking and alcohol consumption on risk of colorectal cancer: a Danish prospective case-cohort study. BMC Cancer 2008, 8:54.

41. Foodcalc 1.3 Computer program 1998. 2009 [http://www.foodcalc.com]

42. Prosky L, Asp NG, Furda I, DeVries JW, Schweizer TF, Harland BF: Determination of total dietary fiber in foods and food products: collaborative study. J Assoc Off Anal Chem 1985, 68:677-679.

43. Tjonneland A, Overvad K, Haraldsdottir J, Bang S, Ewertz M, Jensen OM: Validation of a semiquantitative food frequency questionnaire developed in Denmark. Int J Epidemiol 1991, 20:906-912.

44. Tjonneland A, Haraldsdottir J, Overvad K, Stripp C, Ewertz M, Jensen OM: Influence of individually estimated portion size data on the validity of a semiquantitative food frequency questionnaire. Int J Epidemiol 1992, 21:770-777.

45. Friis S, Poulsen AH, Sorensen HT, Tjonneland A, Overvad K, Vogel U, et al: Aspirin and other non-steroidal anti-inflammatory drugs and risk of colorectal cancer: a Danish cohort study. Cancer Causes Control 2009, 20:731-740.

46. Vogel U, Christensen J, Dybdahl M, Friis S, Hansen RD, Wallin $H$, et al: Prospective study of interaction between alcohol, NSAID use and polymorphisms in genes involved in the inflammatory response in relation to risk of colorectal cancer. Mutat Res 2007, 624:88-100.

47. Miller SA, Dykes DD, Polesky HF: A simple salting out procedure for extracting DNA from human nucleated cells. Nucleic Acids Res 1988, 16:1215.

48. Vangsted AJ, Klausen TW, Ruminski W, Gimsing P, Andersen NF, Gang AO, et al: The polymorphism IL-1beta T-31C is associated with a longer overall survival in patients with multiple myeloma undergoing auto-SCT. Bone Marrow Transplant 2009, 43:539-545.

49. Barlow WE, Ichikawa L, Rosner D, Izumi S: Analysis of case-cohort designs. J Clin Epidemiol 1999, 52:1165-1172.

50. Barlow WE: Robust variance estimation for the case-cohort design. Biometrics 1994, 50:1064-1072.

51. Hansen RD, Sorensen M, Tjonneland A, Overvad K, Wallin H, RaaschouNielsen O, et al: A haplotype of polymorphisms in ASE-1, RAI and ERCC1 and the effects of tobacco smoking and alcohol consumption on risk of colorectal cancer: a Danish prospective case-cohort study. BMC Cancer 2008, 8:54.

52. Raaschou-Nielsen O, Sorensen M, Overvad K, Tjonneland A, Vogel U: Polymorphisms in nucleotide excision repair genes, smoking and intake of fruit and vegetables in relation to lung cancer. Lung Cancer 2007.

53. Raaschou-Nielsen O, Sorensen M, Hansen RD, Frederiksen K, Tjonneland A Overvad K, et al: GPX1 Pro198Leu polymorphism, interactions with smoking and alcohol consumption, and risk for lung cancer. Cancer Lett 2007, 247:293-300.

54. Vogel U, Christensen J, Wallin H, Friis S, Nexo BA, Raaschou-Nielsen O, et al: Polymorphisms in genes involved in the inflammatory response and interaction with NSAID use or smoking in relation to lung cancer risk in a prospective study. Mutat Res 2008, 639:89-100.

55. Sorensen M, Raaschou-Nielsen O, Hansen RD, Tjonneland A, Overvad K, Vogel U: Interactions between the OGG1 Ser326Cys polymorphism and intake of fruit and vegetables in relation to lung cancer. Free Radic Res 2006, 40:885-891.

56. Vogel U, Segel S, Dethlefsen C, Tjonneland A, Saber AT, Wallin H, et al: Associations between COX-2 polymorphisms, blood cholesterol and risk of acute coronary syndrome. Atherosclerosis 2010, 209:155-162.

57. Vogel U, Segel S, Dethlefsen C, Tjonneland A, Saber AT, Wallin H, et al: PPARgamma Pro12Ala polymorphism and risk of acute coronary syndrome in a prospective study of Danes. BMC Med Genet 2009, 10:52.

58. Jensen MK, Rimm EB, Mukamal KJ, Edmondson AC, Rader DJ, Vogel U, et al: The $\mathrm{T} 111 \mathrm{l}$ variant in the endothelial lipase gene and risk of coronary heart disease in three independent populations. Eur Heart J 2009, 30:1584-1589. 
59. Jensen MK, Rimm EB, Rader D, Schmidt EB, Sorensen $T$, Vogel U, et al: S447X variant of the lipoprotein lipase gene, lipids, and risk of coronary heart disease in 3 prospective cohort studies. Am Heart J 2009, 157:384-390.

60. Legrand-Poels S, Zecchinon L, Piret B, Schoonbroodt S, Piette J: Involvement of different transduction pathways in NF-kappa B activation by several inducers. Free Radic Res 1997, 27:301-309.

61. Dring MM, Goulding CA, Trimble VI, Keegan D, Ryan AW, Brophy KM, et al: The pregnane $X$ receptor locus is associated with susceptibility to inflammatory bowel disease. Gastroenterology 2006, 130:341-348.

62. Aitken AE, Richardson TA, Morgan ET: Regulation of drug-metabolizing enzymes and transporters in inflammation. Annu Rev Pharmacol Toxicol 2006, 46:123-149.

63. Wang K, Wan YJ: Nuclear receptors and inflammatory diseases. Exp Biol Med (Maywood) 2008, 233:496-506.

64. Din FV, Dunlop MG, Stark LA: Evidence for colorectal cancer cell specificity of aspirin effects on NF kappa B signalling and apoptosis. Br J Cancer 2004, 91:381-388.

\section{Pre-publication history}

The pre-publication history for this paper can be accessed here: http://www.biomedcentral.com/1471-2407/10/484/prepub

doi:10.1186/1471-2407-10-484

Cite this article as: Andersen et al:: Polymorphisms in NFkB, PXR, LXR and risk of colorectal cancer in a prospective study of Danes. $B M C$ Cancer 2010 10:484.

\section{Submit your next manuscript to BioMed Central and take full advantage of:}

- Convenient online submission

- Thorough peer review

- No space constraints or color figure charges

- Immediate publication on acceptance

- Inclusion in PubMed, CAS, Scopus and Google Scholar

- Research which is freely available for redistribution

Submit your manuscript at www.biomedcentral.com/submit 